\title{
Philip F. Kennedy (éd.), On Fiction and Adab in
} Medieval Arabic Literature

Wiesbaden, Harrassowitz Verlag ( $"$ Studies in Arabic Language and Literature », 6), 2005, xxii+326 p. ISBN 3-447-05182-5

\section{Abdallah Cheikh-Moussa}

\section{(2) OpenEdition}

\section{Journals}

Édition électronique

URL : http://journals.openedition.org/beo/97

DOI : $10.4000 /$ beo.97

ISBN : 978-2-35159-316-5

ISSN : 2077-4079

\section{Éditeur}

Presses de l'Institut français du Proche-Orient

\section{Édition imprimée}

Date de publication : 1 septembre 2009

Pagination : 418-420

ISBN : 978-2-35159-143-7

ISSN : 0253-1623

Référence électronique

Abdallah Cheikh-Moussa, "Philip F. Kennedy (éd.), On Fiction and Adab in Medieval Arabic Literature », Bulletin d'études orientales [En ligne], Tome LVIII | Septembre 2009, mis en ligne le 29 septembre 2009, consulté le 22 septembre 2020. URL : http://journals.openedition.org/beo/97 ; DOI : https://doi.org/ 10.4000/beo.97 
ON FICTION AND ADAB IN MEDIEVAL

ARABIC LITERATURE,

Philip F. Kennedy (éd.),

Wiesbaden, Harrassowitz Verlag ( $"$ Studies in Arabic

Language and Literature », 6), 2005, xxii+326 p.

ISBN 3-447-05182-5

L'ouvrage recensé ici reprend les communications faites dans le cadre $\mathrm{du}$ «Workshop in Medieval Arabic Literature " qui s'est tenu les 21 et 22 avril 2000 à l'université de New York (Department of Middle Eastern Studies). Il est dédié à la mémoire de Rina Drory. Le thème de cet atelier était « Defining Fiction and Adab in Medieval Arabic Literature ».

Ces communications sont au nombre de dix. Elles sont toutes suivies d'une bibliographie, certaines d'annexes. En voici les titres et les noms des auteurs :

- « 'Abbasid Myth and the Human Act: Ibn

'Abd Rabbih and others ", Julia Bray;

- «Min Jumlat al-Jamadāt. The Inanimate in Fictional and Adab Narrative », Daniel Beaumont ;

- «Probability, Plausibility, and 'Spiritual Communication' in Classical Arabic Biography ", Michael Cooperson ;

- «Verses and Taxes: The Function of Poetry in Selected Lierary Akhbār of the Third/Ninth Century », Beatrice Gruendler ;

- "The Use of Composite Form in the Making of the Islamic Historical Tradition », Stefan Leder ;
- «Mas'ūdī and the Reign of al-Amīn: Narrative and Meaning in Medieval Muslim Historiography », Julie S. Meisami ;

- « Serendipity, Resistance, and Multivalency: Ibn Khurradādhbih and his Kitāb al-Masālik wa-l-Mamālik», James E. Montgomery;

- «Al-Ḥārith ibn Zālim and the Trope of Baghy in the Ayyām al-'Arab», Walter Oller;

- «Symbolic Narratives of Self: Dreams in Medieval Arabic Autobiographies ", Dwight F. Reynolds ;

- «Defining Adab by (Re)defining the Adīb: Ibn Abī Țāhir Tayfūr and Storytelling ", Shawkat Toorawa.

Elles sont précédées d'une préface de Philip F. Kennedy dont une bonne partie essaie de restituer l'intervention orale faite par Rina Drory à ce même atelier, six mois environ avant son décès, intervention qui s'intitulait « Modeling Reality through Fiction in Classical Arabic Culture » et qui visait à montrer comment la fiction a été «instrumentalisée » par la société islamique, à ses débuts, pour «modeler la réalité », qu'elle est, dans la littérature 
arabe classique, un creative mode, en concurrence avec un historical/reporting mode, dans la création et le développement de modèles ou de paradigmes du passé comme du présent. Cette concurrence ou opposition correspond à celle qui aurait existé entre les spécialistes de la poésie et ceux du Coran et du hadit.

Auparavant, Philip F. Kennedy fait le constat, pour ne pas dire l'aveu, de l'impossibilité de définir et la fiction et l'adab. C'est d'ailleurs la raison pour laquelle «Defining» qui figurait dans l'intitué de l'atelier a été remplacé par le plus «nébuleux» «On». Et c'est très certainement la question la plus importante que pose ce recueil, riche, touffu parfois, voire contradictoire, mais stimulant toujours la réflexion : les notions (d'aucuns disent « concepts »!) de fiction et d'adabsont-ellesforcément antagonistes et, plus encore, sont-elles vraiment opératoires? Une première réponse est donnée par les communications ellesmêmes : aucune ou presque ne traite d'un ouvrage dit d'adab dans son intégralité, c'est-à-dire comme un tout, non comme un "agrégat» d'ahbār, sérieux ou plaisants, de caractère " historique » ou " fictionnel », de passages en prose ou en vers, dans lequel on puise pour les besoins de la démonstration. Ce faisant, on reconduit, implicitement et délibérément ou non, des jugements tels que ceux que l'on pouvait lire sous la plume des orientalistes, mais pas seulement, des générations précédentes: l'adab cultive l'éclectisme et le coq-à-l'âne. La longue citation de Tarif Khalidi, p. xii-xiii de la préface, tirée d'un compte rendu paru dans Times Literary Supplement ( $\mathrm{n}^{\circ}$ 5061, 31 mars 2000, p. 8) en porte témoignage :
"The Adab style was of necessity eclectic, variegated, full of asides. [...] Clearly, Adab does not correspond to literature in the strict sense; perhaps the happiest synonym so far suggested is [the] Greek Paideia. » L'auteur de ces lignes avoue ignorer ce qu'est la littérature au sens strict alors que l'on parle de l'époque classique ou médiévale (on ne manquera pas d'ailleurs de relever le flottement dans la caractérisation de l'époque considérée par les communications, elle est médiévale pour les uns, classique pour les autres), aussi bien en Occident qu'en Orient.

Comme le lecteur l'aura noté, toutes les communications ont été classées dans l'ordre alphabétique des noms de leurs auteurs, à l'exception de la première, c'est dire l'importance que l'éditeur lui accorde. Et il est vrai que cette intervention se distingue par l'espace consacré à la réflexion "théorique» qui précède l'étude proprement dite. Le postulat de départ est que l'adab doit être pris/ compris, de manière générale, comme une toile de mythes (a web of myth), et l'adib comme un "mythographe" qui ne peut donner sens à son entreprise de sélection et d'arrangement des matériaux [qu'il reprend aux prédécesseurs ?] que si l'interprétation de ces derniers excède les rubriques dans lesquels il les a « rangés ».

Le dénominateur commun à la majeure partie de ces études est de montrer comment les "récits ", qu'ils se veuillent historiques ou anhistoriques, sont " construits», à partir de techniques narratives communes ou similaires, aussi bien structurales que thématiques ou rhétoriques. Il s'agit donc pour l'essentiel d'analyses narratologiques, et on ne peut qu'être frappé par l'absence quasi totale de référence aux études en langue française 
ou arabe consacrées à ce domaine. Abstraction faite de Gérard Genette, qui est cité par Daniel Beaumont, nulle trace dans l'ouvrage des chercheurs francophones tels que Paul Ricoeur, Algirdas J. Greimas ou Pierre Brunel qui a beaucoup écrit sur les mythes littéraires ou la mythopoétique des genres, ni, la thèse de Muhammad alQāḍī exceptée, des études arabophones comme celles de Hammādī Șammūd, al'Ādil Hiḍr [al-Adab 'inda l-Arab, Tunis, Manšūrāt kulliyyat al-ādāb - La Manouba/ Dār Saḥar li-l-našr, 2004], Șālih Bin Rumḍān [al-Rasā̉il al-adabiyya wa-dawruhā fì tațwìr al-natr al-'arabì l-qadìm (mašrū' qirăa ši riyya), Tunis, Manšūrāt kulliyyat al-ādāb - La Manouba, 2001¹ = Beyrouth, Dār al-Farābī, 2007²] ou de 'Abd al-'Azīz Šbīl [Nazariyyat al-ağnās al-adabiyya fì l-turāta alnatrī: ğadaliyyat al-hudūur wa-l-gìizāb, Sfax-
Sousse, Kulliyyat al-ādāb - Sousse/Dār Muhammad 'Alī al-Hāmī, 2001], etc., pour ne citer que les plus récents. Les travaux des « arabisants » français contemporains sont tout autant ignorés, et il est difficile de mettre cet «oubli » sur le compte de je-ne-sais-quelle maîtrise insuffisante de la langue de Molière.

On Fiction an Adab est, certes, une contribution importante à la connaissance de la production narrative arabe prémoderne et qui ne manquera pas de susciter des réactions positives ou négatives. Dommage, cependant, qu'elle ne prenne en compte que la seule, pour ainsi dire, recherche anglo-saxonne.

Abdallah CHEIKH-MOUSSA Professeur à l'Université de Paris 4 Sorbonne 